\title{
Character design and regional identity in Korea since the 1990's
}

\author{
Sun-Young Lim / Min-Soo Kim / Seoul National University / Seoul / Korea
}

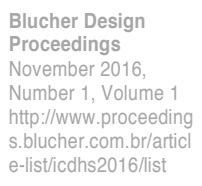

\begin{abstract}
The aim of this study is to research the local government-led identity design by analyzing the official characters of the municipalities. After the autonomous local government system launched in 1990's, each region started to establish a Cl (Community Identity) including regional character in order to promote themselves. The competition between governments was so overheated that in about 7 short years, a majority of the municipalities established Cls. The regional characters look very similar to each other in several aspects. And it is apparent that there is a stereotype. Many of them were designed by KIDP (Korea Institute of Design Promotion) and some design companies that are registered with the Institute. The Cls were created and established hastily in a competitive manner without enough deliberation, and discussion by only a handful of companies. As a result, the characters could not successfully embody the true identity of its representative area.
\end{abstract}

\section{Keywords}

$\mathrm{Cl}$ (Community Identity), identity design, character design, regional character design

\section{Introduction}

Korea has many regional characters. A lot of attention was given to building regional identities since the mid- 1990's. The integrated identity design was especially prevalent, such as logo and emblem design, which also gave birth to many characters. During the following decade, such phenomenon has established itself as a popular trend.

Currently, many establishments that are associated with the Korean government including provinces and government agencies have their own characters. The characters created for the different regions of Korea were explored in more depth.

Regional characters are visually similar. Sometimes it is hard to distinguish one from the other. In other words, it can even be criticized to the extent that they do not successfully embody the true identities of their representative entity. What could be the reasons behind such tendencies?

The cultural, social and political background on how the regional character design projects first started was traced. Furthermore, the development process of these designs is also presented. I took an in-depth look at the 161 characters, of how they were created and conducted visual analysis of the final products. And then, this paper cast a critical eye on government-lead designs.

In this paper, the term, Community Identity $(\mathrm{Cl})$ is used. Many different terms such as GI (Government Identity) or $\mathrm{Cl}$ (City Identity) and $\mathrm{TI}$ (Town Identity) are in use; however Community Identity is chosen as it includes both City and Town.

When a character is used to represent a certain region, it is sometimes referred to as the mascot. However in this research, they are standardized into: character design, and regional character design.

\section{Background on regional character design boom}

The 1990's in Korea has been evaluated as the era of explosive growth in the culture industry. Fine arts, and pop culture were in full bloom and a wide array of cultural goods was produced and consumed. Also, Personal computers started to proliferate, hand in hand with the internet.

In the computer software world, people started to use software that is used to create vector im- 


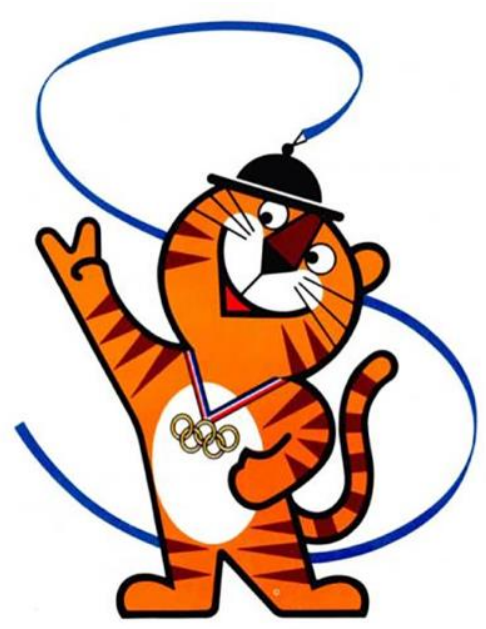

Fig. 1: The mascot for the 88 Seoul Olympics, Hodori ages. Thus the medium for cartoons made a transition from paper to computer, and characters also underwent a change from being 'analog' to 'digital'. In a nutshell, the development of technology made character design possible.

\section{Character Boom}

The mascot for the 88 Seoul Olympics, Hodori, is an anthropomorphized tiger wearing a necklace with the Olympics logo. Through the international mega-event, Korea intended to express its national identity on the international scene in a profound and grand manner. This character being used to represent the Koreans' identity is highly significant. It is clear that a tiger wearing a traditional ribboned dancing hat called the Sang-mo was beloved. This was the moment when the Koreans realized that a character can be used as a 'symbol'.

The creation of this character marked the start of a boom in the cultural industry market. Many took notice that the character industry had become a major part of the cultural industry market, and this field garnered much attention. The government also supported the character design industry. Furthermore, many of the character production and licensing companies were established after the mid 90's. Keeping up with the trend, such started to produce characters for the regions and municipalities.

\section{Launch of autonomous local government system}

Starting from June, 1995, the government shifted from a centralized government into a local self-governing system. Each local government made effort to create a sense of community among its residents, and looked for the ways to promote their region to everyone else. They each had to find unique identities that were markedly different from their neighboring counterparts.

Each region then tried to establish their own identities by utilizing the methods for creating Corporate Identities or Cls, which was prevalent among many of the companies during this era. During this period, competition between regions was becoming ever more heated. It was paramount for each region to establish unique identities based on each of their characteristics and attributes.

In South Korea, there are a total of 17 major regional governments also known as the Metropolitan Councils: the capital city of Seoul, 7 Metropolitan Cities, and 9 Provinces. They are made up of 232 Primary local governments. These regional governments became independent both in administrative and economic aspects from the central government in 1995.

\section{History of regional character design}

\section{The rise of the regional character design}

The regional character design trend emerged with great speed, and peaked at the end of the late 1990 to 2000 , and either became completely obscure just as fast as it rose to popularity, or continued an ambiguous existence.

Bucheon was the first city to make effort to create a city image. Starting from the year 1991, they established their official mark, character and color scheme, and used them in road signs, and street furniture. The other regions followed suit but not until the mid-90's.

In the case of Seoul, the capital of Korea, the first character was designed in 1994. Busan, and Daejeon's were in the following year, 1995. In the late 90's even the minor regional governments that are a part of the provinces each raced on to create their own town symbols, and this movement, all of a sudden, became a nationwide trend. This trend spread from around the capital to the regions further away, and from larger cities, to smaller towns and villages.

Starting from 1996, articles related to $\mathrm{Cl}$ started to make their way onto the pages of newspapers. At first, the articles started off by mainly covering the City image, what symbols are, and introducing cases from other countries. Later, they covered stories on how many regional governments which were racing to develop their own characters, around 1999.

The character boom that started in 1995, peaked in 2000 . According to a research conducted in 
2002, 148 out of 248 governments established individual regional characters. In a short 7 years, more than half of the municipalities jumped into $\mathrm{Cl}$ projects, and this is a clear indication that regional character development was taking place at an incredible speed.

\section{The fall and continuity of the design}

After the mid 2000's, the highly accelerated character design output started to decline. While renewing the homepage, some characters were withdrawn from the "symbol of our city" page. It also seems that many people thought that they did not successfully play the role of a meaningful symbol.

However other regional governments continued to create and renew their characters. Normally the smaller cities and regions that are more reliant on the tourism industry and have specialty regional products have tended to do that. These regions created more characters that could be used at the local festivals, and merchandise. Some of the regions even hold design contests.

Catching up with these contests, educational programs instructing the way to design suitable character appeared. Some video lectures frankly focused making the winner of contests. These lectures provided stereotyped manual in detail from sketching to coloring. Furthermore, they showed how to design many applied poses as well as basic front view.

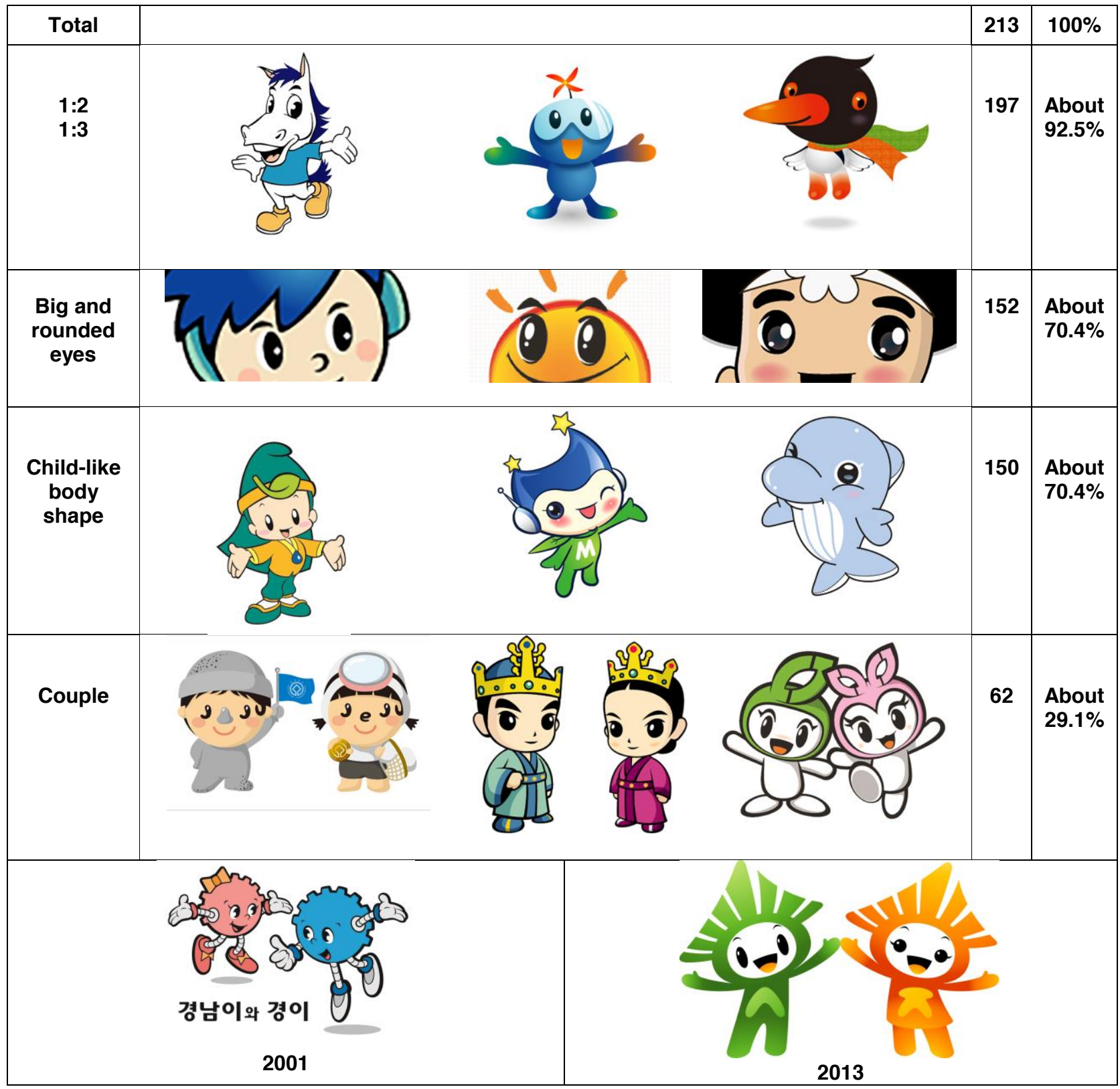

Table 1: Figurative characteristics 


\section{Analysis on regional character design}

Analysis was conducted based on 213 characters. These are about $87 \%$ out of a total number of 245 regional governments. It was focused on figurative characteristics and subject matter.

Figurative characteristics of regional character

Out of the 213 characters, almost of them have big face and small body. The ratio of the head to total height is $1: 2$ or 1:3. Also, many of them had big and rounded eyes, and many of them were representations of young children. They are not easily distinguishable, but some were introduced on the homepages as young, or others are clearly child-like in appearance. The characters were a couple in 62 cases, about $29.1 \%$.

Overall, the color schemes are monotonous. In the past the characters were created in 2D images with black outlines, but those that are created more recently are 3-dimensional, with gradations rather than solid color segments. The expressive style has changed due to the development of technology. However the basic format stayed more or less the same such as the child-like body shape, short arms and legs, large, rounded eyes. Indeed, the characters were quite similar in appearance.

\section{Subject matter of regional character}

According to a study conducted in 2007, many characters were based on the symbols, or specialty products and historical figures. However, a problem arises that certain symbols can overlap over a number of regions. Indeed, there were quite a few cases of disputes. In the cases of regions with the same symbols, creating characters based on those symbols can undermine the uniqueness of their message.

When the characters are based on historical figures, the different regions may argue over who will take over whom. In the case of Nongae and Hong-Gildong, each of them were created by different regions. These are just a few examples and there are many more similar cases.

\begin{tabular}{|c|c|c|c|}
\hline \multicolumn{2}{|c|}{ Nongae Hong-Gildong } \\
\hline Jinju-city & Jangsung-gun & Gangneung-city \\
\hline
\end{tabular}

Table 2 - Same figures manufactured from different regions

There are some reasons why these cases happened. First of all, if the historical figure is famous and high-profile, promoting a region using a character based on him or her would be much more effective. Also, the region can reap profit from the character related merchandise. However, the more important reason is that the predicament arose mainly because of how the government chose to proceed during the process of selecting a motif for "identity" and conveying it in a visual manner.

In fact, the deliberation over the issue of identity and symbol has started much earlier. Korea in the 70's was a time of rapid industrial growth and the nation-wide goal was to advance the field of design for exporting. Because of this, Koreans became strongly focused on showing the world the "color of their identity" However, after the prolonged colonization and war, the traditions were severed, and was extremely difficult to re-acquire the sense of identity as a people. Numerous attempts were made to rebuild our identity while searching for the answers to the questions of who we are, and how we should be represented.

Similarly, the Local Independent governments also faced similar issues when they became independent from the central government in the 90's. I have come to believe that on top of the difficult task of looking for their identities, they also had to think about what their identities should be built upon. 


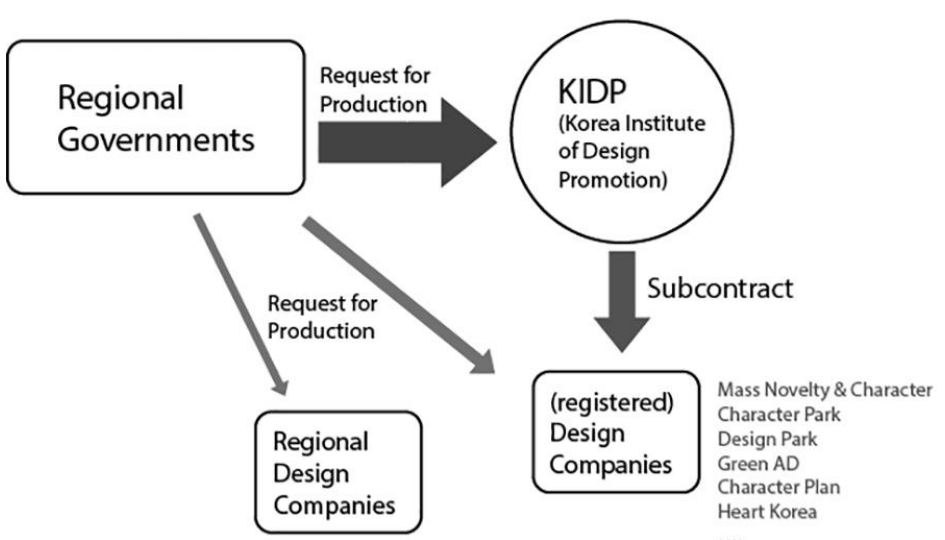

Fig. 2: The process of design production
The process of design production

Many local independent governments commission the KIDP (Korea Institute of Design Promotion) joint $\mathrm{Cl}$ production projects which include character design. The KIDP then subcontracts the project to a design company that is registered with the Institute. In other cases, the local governments are also known to directly award contracts to famous well-established local design companies. These companies created characters for many different governments simultaneously and continuously during the 'boom.' How much thought

the companies put into the identities and individualities of the characters is unknown.

Also, factoring in the fact that character production spread from large cities to smaller ones, it is quite likely that the latter analyzed the formers' characters and created their own in near- imitation.

\section{Conclusion}

The main role or purpose of the regional character is to act as the 'symbol' of a region based on the regional characteristics. Based on what we have reviewed so far, however, the characters shared comparable subjective matter as well as similar formative characteristics. It can also be deduced that such canon almost stayed the same for 30 years. These issues are may be the limitations that character design has. However the following is gathered as the reasons behind such traits.

1. Insufficient discussion on the issue of identity.

2. How competition riddled, fast paced, $\mathrm{Cl}$ design led to character design without copious amounts of discussions and deliberation.

3. How the characters were repeatedly created through the same institution, and a few select companies. There have been much self-criticism on the regional character design, and it is true that this pushed the field of design forward. However there are many who are voicing that regional characters are useless, and keeping a critical eye on the government design administration is very important.

\section{References}

Cho, J. (2007). 'A Plan on Improving of the Competitiveness for Kyeungsangbuk-do's Regional Character', Review of Cultural Economics, Vol.10 (No.2): 15-37.

Hwang, C. (2002). A study on application of the character design of the local autonomous entity, Diss., UIsan Univ.

Lee, Y., Won, Y., Kim, H., Kim, E. and Lee, D. (1999). A Study on Development Plan for Character Industry, Korea Cultural Policy Institute.

Kim, M. (2009). Korean Urban Design Exploration, Greenbee.

"Renew Insignia-Symbolic Icon" Changing City Image." Dong-A Ilbo, May 11, 1996.

"Competition between Regional Governments to develop Regional Character" Maeil Business Newspaper. Mar. 1, 1999

\section{Biographical note}

Sun-Young Lim, Master of Fine Arts Candidate in Design History and Cultural Studies at Seoul National University. Bachelor of Fine Arts in Painting and Design at Seoul National University.

Min-Soo Kim, Professor and Director of Design History and Cultural Studies, graduate course of Seoul National University(www.snu-dhc.com); Received Ph.D from New York University in USA.; Former chief editor of The Journal of Design Culture and Criticism (JDCC, 1999 2002), the first journal of cultural history, theory and criticism on design in Korea. 